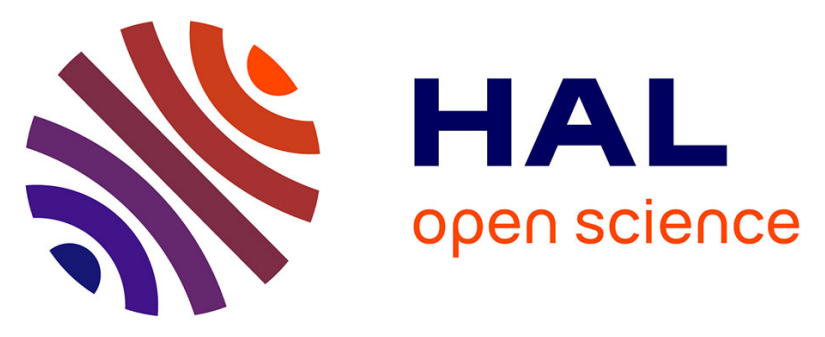

\title{
Assessment of the efficacy of a local steroid rescue treatment administered 2 days after a moderate noise-induced trauma in guinea pig
}

Elisabeth Mamelle, Naila El Kechai, Victor Adenis, Yann Nguyen, Olivier Sterkers, Florence Agnely, Amélie Bochot, Jean-Marc Edeline, Evelyne Ferrary

\section{To cite this version:}

Elisabeth Mamelle, Naila El Kechai, Victor Adenis, Yann Nguyen, Olivier Sterkers, et al.. Assessment of the efficacy of a local steroid rescue treatment administered 2 days after a moderate noise-induced trauma in guinea pig. Acta Oto-laryngologica, 2018, 138 (7), pp.610-616. 10.1080/00016489.2018.1438659 . hal-02111940

\author{
HAL Id: hal-02111940 \\ https://hal.science/hal-02111940
}

Submitted on 17 May 2019

HAL is a multi-disciplinary open access archive for the deposit and dissemination of scientific research documents, whether they are published or not. The documents may come from teaching and research institutions in France or abroad, or from public or private research centers.
L'archive ouverte pluridisciplinaire HAL, est destinée au dépôt et à la diffusion de documents scientifiques de niveau recherche, publiés ou non, émanant des établissements d'enseignement et de recherche français ou étrangers, des laboratoires publics ou privés. 


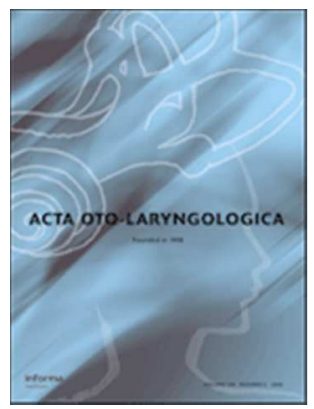

\section{Assessment of the efficacy of a local steroid rescue} treatment administered 2 days after a moderate noiseinduced trauma in guinea pig

\begin{tabular}{|r|l|}
\hline Journal: & Acta Oto-Laryngologica \\
\hline Manuscript ID & SOTO-2017-0576 \\
\hline Manuscript Type: & Regular \\
\hline Classification Scheme: & inner ear \\
\hline Keywords: & $\begin{array}{l}\text { Dexamethasone phosphate; guinea pigs; hearing loss; noise-induced; } \\
\text { hydrogel; liposomes }\end{array}$ \\
\hline \multicolumn{2}{|l}{} \\
\hline
\end{tabular}

SCHOLARONE $^{\text {Im }}$

Manuscripts 


\title{
Assessment of the efficacy of a local steroid rescue treatment administered 2 days after a moderate noise-induced trauma in guinea pig
}

\author{
A local treatment after noise trauma in guinea pig \\ Elisabeth Mamelle, Naila El Kechai, Victor Adenis, Yann Nguyen, Olivier Sterkers, Florence Agnely, \\ Amélie Bochot, Jean Marc Edeline, Evelyne Ferrary
}

\begin{abstract}
Objectives: Intratympanic injection of corticosteroids membrane after noise-induced hearing loss is an accepted alternative to general administration. We investigated the effect on hearing of a hyaluronic acid gel with liposomes loaded with dexamethasone (DexP) administered into the middle ear.

Methods: An acute acoustic trauma was performed to 13 guinea pigs for a period of 1 hour on

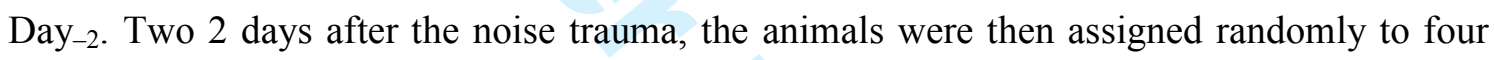
experimental groups: control without gel, gel injection, gel containing free DexP, gel containing DexP loaded into liposomes. Auditory thresholds were measured with Auditory Brainstem Response before Day-2 and at Day 0, Day 7 and Day 30 after noise trauma.

Results: Seven days after, a complete hearing recovery was observed in the control group at all frequencies apart from $8 \mathrm{kHz}$, and no recovery was observed in the three groups receiving a gel injection. Thirty days after trauma, all of the animals had recovered normal hearing, apart from at the $8-\mathrm{kHz}$ frequency, with similar auditory thresholds.

Conclusions: Local DexP administration $48 \mathrm{~h}$ after a mild acoustic trauma did not improve hearing recovery, even with a sustained release in a specific gel formulation designed for inner ear therapy.
\end{abstract}

Key words: Dexamethasone phosphate; guinea pigs; hearing loss; noise-induced; hydrogel; liposomes 


\section{Introduction}

Exposure to intense noise is frequently associated with non-genetic (acquired) hearing loss in adult subjects. The traumatizing noise may be continuous, repetitive impulsive (industrial noises), or pure impulsive (explosions, gunshots)[1]. Acute acoustic trauma leads to mechanical and metabolic damage to the cochlea. The mechanical damage is due to excessive movements of the basilar membrane leading to loss of hair cells, impaired stereocilia, and collapse of supporting cells[2]. The subsequent metabolic damage includes ionic disorders involving an intracellular influx of potassium or calcium, excitotoxicity following excessive release of glutamate, and oxidative stress due to the production of free radicals[3]. These mechanisms can lead to relatively rapid cell death by necrosis and/or apoptosis. Part of the initial noise-induced hearing loss is only temporary, and may recover as a result of cochlear repair mechanisms[3, 4]. However, exposure to impulse noise typically results in substantial permanent hearing loss.

At a clinical level, common treatments after noise-induced hearing loss consist of resting in a silent environment, administration of corticosteroids which may or may not be associated with vasodilator drugs, antioxidant drugs, hyperbaric oxygen therapy or normovolemic hemodilution[1]. Various pharmacologic compounds such as corticosteroids, apoptosis inhibitors, and antioxidants have been tested in animal models with various levels of noiseinduced hearing $\operatorname{loss}[1,2]$. In these noise trauma animal models, therapies have been administered either before or after noise exposure, and these were effective to varying degrees with regard to hearing protection.

In an earlier study, we demonstrated that a liposomal hyaluronic acid gel loaded with dexamethasone phosphate (DexP) injected into the middle ear of guinea pigs resulted in a high drug concentration in the perilymph as well as a sustained release of the drug for up to 30 days[5]. The aim of the present study was to determine whether this local treatment could have a therapeutic effect in guinea pigs when applied 2 days after a moderate acoustic trauma, 
a clinically relevant condition.

\section{Materials and methods \\ Animals}

Thirteen male Hartley albino guinea pigs (Charles River, L'Arbresle, France) were used in the study weighing 300-500 $\mathrm{g}$ with auditory thresholds in the normal range[6]. Animal care and experimental procedures were conducted in accordance with the guidelines established by the European Communities Council Directive (2010/63/EU Council Directive Decree), and were approved by the local ethics committee ( $\mathrm{N}^{\circ}$ AP 2014-23).

\section{Study design (Fig. 1)}

Fig. 1 Experimental protocol near here

After the initial determination of the auditory threshold by Auditory Brainstem Responses (ABR), all of the animals were subjected to noise-exposure at $\mathrm{D}_{-2}$. Two days later, at $\mathrm{D}_{0}$, the audiogram was re-tested with $\mathrm{ABR}$ to evaluate the hearing loss induced by the acoustic overexposure. Following this post-trauma ABR test, animals were assigned randomly to four experimental groups:

1. control without gel injection but with the bulla opened (eight ears),

2. hyaluronic acid gel injection without DexP (HA; six ears),

3. hyaluronic acid gel containing free DexP (HA-DexP; six ears),

4. hyaluronic acid gel containing DexP loaded into liposomes (HA-DexP-Lip; five ears). In all the animals in these groups, both ears were used and each ear was considered to be an independent measurement. In the HA-DexP-Lip group, one animal had only one ear injected with the gel (which explains the odd number of ears in this group). The hearing thresholds were recorded again at Day $7\left(D_{7}\right)$ and Day $30\left(D_{30}\right)$ for all groups.

\section{Materials}


Dexamethasone sodium phosphate (DexP, Mw 516.4 Da, purity 98\%) was obtained from Fagron (Amsterdam, The Netherlands). Egg phosphatidylcholine (EPC, purity 96\%) was provided by Lipoid GmbH (Ludwigshafen, Germany). Cholesterol (Chol) was purchased from Sigma-Aldrich Co. (St Louis, MO, USA). 1,2-Distearoyl-sn-glycero-3phosphoethanolamine-N-[methoxy-poly-(ethyleneglycol) 2000] (DSPE-PEG2000, purity > 99\%) was obtained from Avanti Polar Lipids, Inc. (Alabaster, AL, USA). Sodium hyaluronate (HA, Mw 1.5 MDa, purity 95\%) was provided by Acros Organics (New Jersey, USA). All other chemicals were of analytical grade.

\section{Preparation of hyaluronic acid (HA) gel formulations}

DexP-loaded PEGylated liposomes (DexP-Lip) were prepared by the thin film method as previously described[7]. Briefly, lipid film composed of EPC:Chol:DSPE-PEG2000 (60:35:5 mol\%) was prepared using rotary evaporation. The lipid film was hydrated with $100 \mathrm{mg} / \mathrm{mL}$ DexP solution in Milli-Q water. The liposome suspension was extruded to achieve a final size of $140 \mathrm{~nm}$. Non-encapsulated DexP was eliminated by dialysis using cellulose dialysis membranes with a molecular weight cut-off of $15 \mathrm{kDa}$ (Spectrum Laboratories, Inc, CA, USA) against HEPES/ $\mathrm{NaCl}$ buffer $(10 / 115 \mathrm{mM}, \mathrm{pH} 7.4)$ at $4^{\circ} \mathrm{C}$ for $48 \mathrm{~h}$ with repeated changes of buffer and protection from light. The mean encapsulation efficiency for DexP-Lip was $182 \pm 30 \mathrm{mg}$ DexP/g lipid.

HA and HA-DexP gels were prepared by dissolving HA $(2.28 \% \mathrm{w} / \mathrm{v})$ in HEPES/ $\mathrm{NaCl}$ buffer $(10 / 115 \mathrm{mM}, \mathrm{pH} 7.4)$ and in $10 \mathrm{mg} / \mathrm{mL}$ of DexP solution, respectively (DexP dissolved in HEPES/NaCl buffer 10/115 mM, pH 7.4). For the preparation of liposomal gel (HA-DexPLip), HA $(2.28 \% \mathrm{w} / \mathrm{v})$ was dissolved in the liposome suspension at $80 \mathrm{mM}$ final lipid concentration with a DexP concentration of $10 \mathrm{mg} / \mathrm{mL}$. The gels were then homogenized by vortex mixing for $5 \mathrm{~min}$, maintained at room temperature for $1 \mathrm{~h}$ and then stored at $4{ }^{\circ} \mathrm{C}$ for at least $12 \mathrm{~h}$ before in vivo injection.

\section{Exposure to traumatic sound}


Animals, placed individually in a wire mesh cage $(23 \times 23 \times 15 \mathrm{~cm})$, were exposed for $1 \mathrm{~h}$ to a traumatic tone (5 $\mathrm{kHz}$ pure tone, $100 \mathrm{~dB}$ SPL) in an acoustically isolated chamber (IAC model AC2). The pure tone was generated by a wave generator (Hewlett-Packard, model HP 8903B), amplified (Prism-Audio, model LA-150M) and sent to two piezoelectric tweeters (Motorola, model KSN 1005) located on each side of the cage. The sound delivery system was calibrated to obtain $100 \pm 5 \mathrm{~dB}$ at various locations in the cage, verified by a calibrated type I precision sound level meter (B\&K model 2235). As in a previous study[8], visual inspection of the animal during exposure indicated that there was no preferred orientation of the animal with regard to the speakers.

\section{Audiograms determined from Auditory Brainstem Response (ABR)}

The audiograms from the guinea pigs were evaluated by recording the ABR following an auditory stimulus. The ABR test was performed on both ears before acoustic trauma $\left(\mathrm{D}_{-2}\right)$ and after trauma $\left(\mathrm{D}_{0}, \mathrm{D}_{7}\right.$, and $\left.\mathrm{D}_{30}\right)$, under gas general anesthesia (isoflurane). Tone bursts of $50 \mathrm{~ms}$ duration were delivered at $1,4,8,16,24$, and $32 \mathrm{kHz}$, by a high frequency transducer (Etymotic Research ER1) connected to an external ear canal probe. The ABR were recorded via subcutaneous electrodes (SC25, Neuro-Services) placed subcutaneously in the leg, the vertex, and the ipsilateral retro-auricular side of the analyzed ear. The ABR were collected using a commercial interface and software (RT Otophy Lab, Echodia, France), and were determined from $80 \mathrm{~dB}$, with $5 \mathrm{~dB}$ decreasing steps. The thresholds corresponded to the minimal intensity for which an ABR wave (usually wave 3) was clearly detected. To minimize the use of animals (according to the $3 \mathrm{R}$ rule), both ears from each animal were used, and each ear was considered to be an independent repetition.

\section{Injection procedure}

Gel injection into the middle ear (HA, HA-DexP or HA-DexP-Lip) was performed at $\mathrm{D}_{0}$, under general gas anesthesia (isoflurane). Body temperature was maintained around $37^{\circ} \mathrm{C}$ by a controlled heating tap. To guarantee precise application of the gel on the round window 
under microscopic view, the gel was injected into the middle ear after a surgical approach instead of a direct intratympanic injection. The retro-auricular skin was shaved and cleaned with povidone-iodine. Local anesthesia was administered by the injection of lidocaine hydrochloride $(0.5 \mathrm{~mL}, 1 \%)$ into the subcutaneous tissues to complete the general anesthesia. After a retro-auricular incision, the muscles were gently pushed aside from the bone and the tympanic bulla was carefully opened using a 2-mm diamond bur to drill the bone (Collin, NSK, Nakashima, Japan) allowing visualization of the cochlea as well as the round window. The gel was injected using a $1 \mathrm{~mL}$ syringe equipped with a $29 \mathrm{G}$ needle (diameter $=0.16 \mathrm{~mm}$, length $=88 \mathrm{~mm}$, B. Braun). The volume of gel injected was $150 \pm 20 \mu \mathrm{L}$ (DexP dose: $1.5 \pm$ $0.2 \mathrm{mg}$ ), depending on the size of the bulla. This procedure was performed under binocular loupe to inject the gel on the round window, and then to completely fill the bulla. The muscle and skin were then sutured with a 3.0 Vicryl suture (Ethicon, Cincinnati, OH, USA). After the injection procedure, the guinea pigs received an intramuscular injection of antibiotic prophylaxis (Enrofloxacine Bayer, Leverkusen, Germany). A general analgesic (Tolfedine 1 $\mathrm{mg} / \mathrm{kg}$ i.p.) was delivered at the end of surgery. In control animals, the same surgical procedure was performed but without any gel injection.

\section{Statistical analysis}

Results are expressed as mean \pm SEM. GraphPad Prism 7 software was used for statistical analysis. Non-parametric tests were performed, and statistical analysis of the hearing thresholds was conducted using two-way or one-way analysis of variance (ANOVA), with Tukey's post-hoc test. A p value $<0.05$ was considered to be statistically significant.

\section{Results}

Before noise exposure ( $\left.\mathrm{D}_{-2}\right)$, auditory thresholds determined between 1 and $32 \mathrm{kHz}$ were in the range of what has previously been described in guinea pigs[6]. Auditory thresholds, before noise exposure, were equivalent among the individuals and between groups (two-way 


\begin{abstract}
ANOVA, ns; Fig. 2). Two days after noise exposure, a noise-induced threshold shift $\left(\mathrm{D}_{-2} v s\right.$. $\mathrm{D}_{0}$ ) was observed at all frequencies apart from $1 \mathrm{kHz}$, and was similar between the different experimental groups (Fig. 2). The mean hearing loss recorded at $8 \mathrm{kHz}$ was $29 \pm 3 \mathrm{~dB}$, and at $16 \mathrm{kHz}$, it was $24 \pm 3 \mathrm{~dB}$. For 4, 24 and $32 \mathrm{kHz}$, a hearing loss around $15 \mathrm{~dB}$ was observed (14 $\pm 2 \mathrm{~dB}, 14 \pm 3 \mathrm{~dB}$ and $16 \pm 2 \mathrm{~dB}$, respectively).
\end{abstract}

Fig. 2 Pre- and post-trauma ABR thresholds near here

Seven days after noise-exposure $\left(D_{7}\right)$, a total recovery of the thresholds was observed in the control group at 4, 16, 24 and $32 \mathrm{kHz}$ (Fig. 3). However, a $23 \pm 4 \mathrm{~dB}$ hearing loss was still observed at $8 \mathrm{kHz}$ (two-way ANOVA, $\mathrm{p}<0.0001$ ). In the other groups, in which gel was applied in the bulla, whatever the formulation (HA, HA-DexP or HA-DexP-Lip), no recovery was observed at $\mathrm{D}_{7}$ : $\mathrm{ABR}$ thresholds were similar to the post-trauma $\mathrm{ABR}$ thresholds measured at $\mathrm{D}_{0}$ at all frequencies (two-way ANOVA, ns; Fig. 3).

Fig. 3 Post-trauma thresholds at $\mathrm{D}_{7}$ (solid black line) near here

One month after the trauma $\left(\mathrm{D}_{30}\right)$, total recovery was observed in all groups compared to pretrauma thresholds (apart from $8 \mathrm{kHz}$ frequency in each group), with no differences among all groups (Fig. 4). In the control group, at 4, 16, 24 and $32 \mathrm{kHz}$ frequencies, ABR thresholds remained stable at $D_{30}$, compared to $D_{7}$, with no difference compared to pre-trauma $A B R$ thresholds (two-way ANOVA, ns; Fig. 4). At $8 \mathrm{kHz}$, the hearing loss was $20 \pm 3 \mathrm{~dB}$ for the control group, $15 \pm 6 \mathrm{~dB}$ for the HA group, $14 \pm 7 \mathrm{~dB}$ for the HA-DexP group, and $13 \pm 5 \mathrm{~dB}$ for the HA-DexP-Lip group.

Fig. 4 Post-trauma thresholds at $\mathrm{D}_{30}$ (solid black line) near here 


\section{Discussion}

In the present study, acoustic traumas were performed on guinea pigs to test the efficacy of DexP when delivered from a local gel 2 days after noise exposure. Guinea pig is a model commonly used to study hearing disabilities because hearing thresholds are age-dependent when evaluated 1 month after birth (Table 1)[6,9]. However, there are differences in hearing between pigmented and albino guinea pigs. Albino guinea pigs usually have lower hearing than pigmented guinea pigs, especially in the midfrequencies[10]. Thus, the albino model might experience poorer recovery probably related to the properties of the stria vascularis which lacked melanin and showed a different glutathione distribution[10, 11]; however, this point remains under debate because similar noise trauma experiments performed in both models showed higher hearing loss in pigmented guinea pigs (Table 1)[11-14].

With the acoustic trauma performed in the present experimental protocol, a temporary threshold shift was observed at most frequencies apart from $8 \mathrm{kHz}$, which showed a permanent threshold shift of $20 \mathrm{~dB}$ at 7 and 30 days in the control group. These data are consistent with those of Gourévitch et al., who demonstrated that a single trauma could produce a temporary threshold shift restricted to 6-9 days[8]. Indeed, initial noise-induced hearing loss can partially recover with cochlear repair mechanisms that promote cell recovery, and antioxidant intracellular reactions of defense mechanisms[4].

The acoustic trauma delivered in this study was centered on the $5 \mathrm{kHz}$ frequency which usually leads to a threshold shift an octave above the frequency of the traumatic sound[15]. More severe noise traumas $(>105 \mathrm{~dB})$ were usually performed in other studies to test corticosteroid efficacy in albino guinea pigs, with various duration times from 20 min to $48 \mathrm{~h}$ (Table 1). Harrop-Jones et al. found greater temporary ABR thresholds with a $2 \mathrm{~h}$ acoustic trauma (narrow bandpass $4-8 \mathrm{kHz}$ ) at $105 \mathrm{~dB}$, similar to the present noise trauma, especially at 4 and $16 \mathrm{kHz}$, with hearing losses around $40-50 \mathrm{~dB}$ and $40-20 \mathrm{~dB}$, respectively [16]. 
Interestingly, they demonstrated a benefit from the OTO-104 gel $(6 \%$ dexamethasone in poloxamer gel) 10 days after the trauma at $4 \mathrm{kHz}$ but not $8 \mathrm{kHz}$, when it was injected 2 days after noise exposure, and at $8 \mathrm{kHz}$ when OTO-104 was injected 3 days after trauma. When the OTO-104 gel was applied before noise exposure, otoprotection was demonstrated at 4, 8 and $16 \mathrm{kHz}$ frequencies with the two-noise trauma paradigms tested: $2 \mathrm{~h}$ at $105 \mathrm{~dB}$ or $110 \mathrm{~dB}$. In their study, only $50 \mu \mathrm{l}$ gel was injected through the tympanic membrane whereas the present protocol used a retroauricular approach to fill the whole bulla (around $150 \mu 1$ ).

Table 1 near here

In contrast to invasive systems such as an osmotic pump, which could deliver high dexamethasone concentrations locally for outer hair cell protection[1, 17], the local drug delivery system tested in the present study was specific HA gels delivering DexP. They were designed for inner ear therapy, with two different kinetic release mechanisms. Indeed, the HA gels could achieve longer residence times in the middle ear in contact with the round window whereas the liquid solution usually injected is rapidly evacuated through the Eustachian tube[7]. Furthermore, one gel injection could ensure a longer release delivery into the bulla and thus could avoid repeated injections. DexP loaded into liposomes contained within HA gel has been shown to ensure a sustained release with elevated concentrations for up to 30 days, compared to free DexP within HA gel, which could be released for up to 15 days[5].

Nevertheless, in the present noise-induced hearing loss procedure, similar spontaneous hearing recovery was observed in the treated animals compared to non-treated ones. Moreover, in animals with gel injections, a delayed recovery was observed at $\mathrm{D}_{7}$, compared to the control group, which could be due to a conductive hearing loss induced by the gel viscosity that filled the whole bulla and surrounded the traumatized ossicular chain. These rheological behaviors and the presence of the gel at $\mathrm{D}_{7}$ around the ossicular chain that was overexposed to noise[5] may explain the delay in recovery observed in the three experimental groups. 
The use of corticosteroids for hearing protection during noise over-exposure in animals has been widely described in the literature (Table 1); however, there was some discrepancy with regard to their success in hearing recovery. When dexamethasone was administered locally at different concentrations before noise exposure, efficient hearing thresholds could be observed 7 days after trauma $[16,17]$. At variance, 14 days or 30 days after noise exposure, immediate local administration of steroid in a continuous delivery form (mini-osmotic pump, intratympanic injection, gelatin sponge) was shown to reduce hair cell loss (mostly outer hair cells), accelerate hearing recovery, but demonstrated various impacts on functional hearing outcomes (Table 1)[1, 13, 14]. Indeed Sendowski et al showed 16\% of outer hair cell loss when methylprenisolone was administrated with an osmotic pump before and after acoustic trauma compared to a control group (46\%) with an earlier hearing recovery but finally, similar auditory thresholds on all frequencies at 14 days[1]. In opposition, at similar severe acoustic trauma, Chi et al demonstrated at 3 and 4 weeks a stable hearing recovery and greater outer hair cell loss $(67 \%)$ with a local dexamethasone administration. The correlation between functional and histological outcomes remains unclear.

With regard to delayed injection, from $24 \mathrm{~h}$ up to several days after noise exposure, a significant decrease in treatment efficiency was seen in albino guinea pigs[13, 16]. As previously described, early administration of corticosteroids can prevent anticipated acoustic trauma such as gunshot in the military operating field or in noise trauma surgery. However, Tran Ba Huy and Sauvaget found that the mean delay between first symptoms and medical visit was 3.1 days for idiopathic sensorineural hearing loss in 321 patients at emergency care[18]. Therefore, a 48-h delay between the acoustic trauma and dexamethasone injection was chosen in the present study to replicate patient clinics which present unpredictable noiseinduced hearing loss. Patients presenting unexpected acoustic trauma could be considered to have a sensorineural disorder. In this context, it is reasonable to assume that patients with acoustic trauma will not benefit from such local treatment. Indeed, dexamethasone locally 
applied may act more like an otoprotective drug with a potential impact on temporary threshold shift rather than a permanent threshold shift after noise exposure.

\section{Conclusion}

The present study demonstrated a permanent hearing loss, at $8 \mathrm{kHz}, 1$ month after a mild noise trauma of $105 \mathrm{~dB}$ in albino guinea pigs. Dexamethasone in liposomes included in HA gel passively diffused through the round window $48 \mathrm{~h}$ after the acoustic trauma failed to promote additional or faster hearing recovery at $4,16,24$ and $32 \mathrm{kHz}$ compared to spontaneous recovery. The drug concentration in the inner ear and both the time and form of drug delivery must be carefully considered after acoustic trauma to ensure a potential benefit.

\section{References}

1. Sendowski I, Abaamrane L, Ra FY, et al. Therapeutic efficacy of intra-cochlear administration of methylprednisolone after acoustic trauma caused by gunshot noise in guinea pigs. Hear Res 2006;221:119-127. doi: 10.1016/j.heares.2006.08.010

2. Coleman JKM, Littlesunday C, Jackson R, Meyer T. AM-111 protects against permanent hearing loss from impulse noise trauma. Hear Res 2007;226:70-78. doi: 10.1016/j.heares.2006.05.006

3. Puel J-L, Ruel J, D'Aldin CG, Pujol R. Excitotoxicity and repair of cochlear synapses after noise-trauma induced hearing loss. Neuroreport 1998;9:2109-2114.

4. Kopke R, Allen KA, Henderson D, et al. A Radical demise : toxins and trauma share common pathways in hair cell death. Ann N Y Acad Sci 1999;884:171-191.

5. El Kechai N, Mamelle E, Nguyen Y, et al. Hyaluronic acid liposomal gel sustains delivery of a corticoid to the inner ear. J Control Release 226:248-257. doi: 10.1016/j.jconrel.2016.02.013

6. Gourévitch B, Edeline JM (2011) Age-related changes in the guinea pig auditory cortex: Relationship with brainstem changes and comparison with tone-induced hearing loss. Eur J Neurosci 2016;34:1953-1965. doi: 10.1111/j.1460-9568.2011.07905.x

7. El Kechai N, Bochot A, Huang N, et al. Effect of liposomes on rheological and syringeability properties of hyaluronic acid hydrogels intended for local injection of drugs. Int J Pharm 2015;487:187-196. doi: 10.1016/j.ijpharm.2015.04.019

8. Gourévitch B, Doisy T, Avillac M, Edeline J. Follow-up of latency and threshold shifts of auditory brainstem responses after single and interrupted acoustic trauma in guinea pig. Brain Res 2009;1304:66-79. doi: 10.1016/j.brainres.2009.09.041

9. Conlee JW, Abdul-Baqi KJ, McCandless G, Creel D. Effects of aging on normal hearing loss and noise-induced threshold shift in albino en pigmented guina pigs. Acta Otolaryngol 1988;106:64-70.

10. Conlee JW, Abdul-baqi KJ, Mccandless GA, Creel DJ. Differential susceptibility to noise-induced permanent threshold shift between albino and pigmented guinea pigs. Hear 
Res 1986;23:81-91.

11. Landegger LD, Honeder C, Zhu C, et al. Noise trauma and systemic application of the selective glucocorticoid receptor modulator compound A. Journan Negat Results Biomed 2016;15:1-9. doi: 10.1186/s12952-016-0053-0

12. Wang B, Liu Y, Chi F, et al. Dexamethasone suppresses cochlear hes1 expression after noise esposure. Acta Otolaryngol 2013;133:233-8.

13. Chi FL, Yang MQ, Zhou YD, Wang B. Therapeutic efficacy of topical application of dexamethasone to the round window niche after acoustic trauma caused by intensive impulsu noise in guinea pigs. J Laryngol Otol 2011;7:673-685.

14. Zhou Y, Zheng H, Shen X, et al. Intratympanic administration of methylprednisolone reduces impact of experimental intensive impulse noise trauma on hearing. Acta Otolaryngol 2009;129:602-607. doi: 10.1080/00016480802342424

15. Huetz C, Guedin M, Edeline J.Neural correlates of moderate hearing loss : time course of response changes in the primary auditory cortex of awake guinea-pigs. Front Syst Neurosci 2014;8:1-12. doi: 10.3389/fnsys.2014.00065

16. Harrop-Jones A, Wang X, Fernandez R, et al.The Sustained-Exposure Dexamethasone Formulation OTO-104 Offers Effective Protection against Noise-Induced Hearing Loss. Audiol Neurotol 2016;21:12-21. doi: 10.1159/000441814

17. Takemura K, Komeda M, Yagi M, Himeno C.Direct inner ear infusion of dexamethasone attenuates noise-induced trauma in guinea pig. Hear Res 2004;196:58-68. doi: 10.1016/j.heares.2004.06.003

18. Tran Ba Huy P, Sauvaget E.Idiopathic sudden sensorineural hearing loss is not, at this time, an otologic emergency. Ann Otolaryngol Chir Cervicofac 2007;124:66-71. doi: 10.1016/j.aorl.2006.12.003

19. Heinrich U-R, Strieth S, Schmidtmann I, et al. Dexamethasone prevents hearing loss by restoring glucocorticoid receptor expression in the guinea pig cochlea. Laryngoscope 2016;126:29-34. doi: 10.1002/lary.25345

20. Li ML, Lee LC, Cheng YR, et al. A novel aerosol-mediated drug delivery system for inner ear therapy: intratympanic aerosol methylprednisolone can attenuate acoustic trauma. IEEE Trans Biomed Eng 2013;60:2450-60. 


\section{Figure Captions}

Fig. 1 Experimental protocol

Fig. 2 Pre- and post-trauma ABR thresholds

ABR thresholds in all animals were recorded before (dashed line, $\mathrm{D}_{-2}$ ) and after (solid line, $\mathrm{D}_{0}$ ) noise exposure $(5 \mathrm{kHz}, 100 \mathrm{~dB}, 1 \mathrm{~h})$ and are shown for comparison (two-way ANOVA; $* * * * \mathrm{p}<0.0001$ Tukey's post-hoc test). Values are mean \pm SEM (25 ears).

Fig. 3 Post-trauma thresholds at $\mathrm{D}_{7}$ (solid black line)

Pre-trauma $\mathrm{ABR}$ thresholds at $\mathrm{D}_{-2}$ (dashed gray line) and post-trauma $\mathrm{ABR}$ thresholds at $\mathrm{D}_{0}$ (solid gray line) are shown for comparison. ABR thresholds at $\mathrm{D}_{7}$ (solid black line) are represented by (A) control group (trapezoid, eight ears), (B) HA group (squares, six ears), (C) HA-DexP group (diamonds, six ears), (D) HA-DexP-Lip group (triangles, five ears). Values are mean \pm SEM. Hearing recovery was observed in the control group (A) in ABR thresholds at 16 and $24 \mathrm{kHz}\left(\mathrm{D}_{7}\right)$ compared to post-trauma $\left(\mathrm{D}_{0}\right)$ (two-way ANOVA; *p $<0.05$, $* * \mathrm{p}<0.002$; Tukey's post-hoc test).

Fig. 4 Post-trauma thresholds at $\mathrm{D}_{30}$ (solid black line)

Pre-trauma $\mathrm{ABR}$ thresholds at $\mathrm{D}_{-2}$ (dashed gray line) and post-trauma $\mathrm{ABR}$ thresholds at $\mathrm{D}_{0}$ (solid gray line) are shown for comparison. $\mathrm{ABR}$ thresholds at $\mathrm{D}_{30}$ (solid black line) are represented by (A) control group (trapezoid, eight ears), (B) HA group (squares, six ears), (C) HA-DexP group (diamonds, six ears), (D) HA-DexP-Lip group (triangles, five ears). Values are mean \pm SEM. Total recovery at $\mathrm{D}_{30}$ was observed in all groups compared to pre-trauma thresholds $\left(\mathrm{D}_{-2}\right)$, apart from $8 \mathrm{kHz}$ frequency in each group, with no significant differences among all groups (two-way ANOVA; ${ }^{*} \mathrm{p}<0.02,{ }^{* *} \mathrm{p}<0.002,{ }^{* * *} \mathrm{p}<0.0001$ Tukey's post-hoc test). 


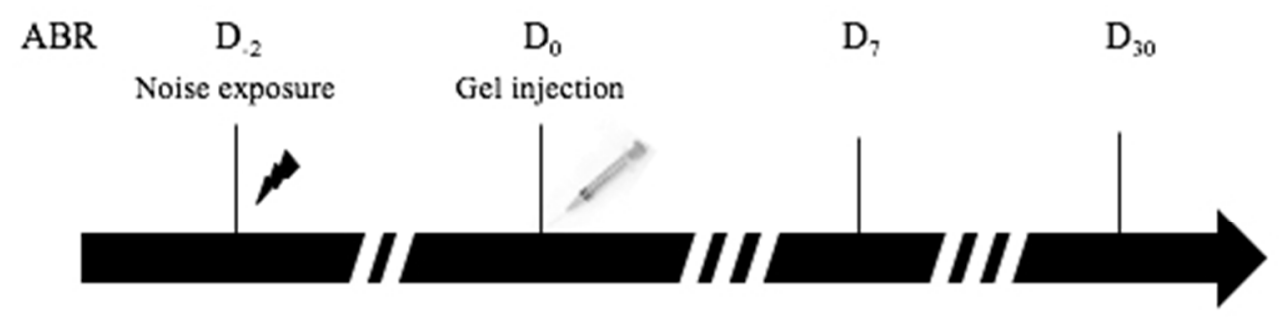

Fig. 1 Experimental protocol

$172 \times 44 \mathrm{~mm}(72 \times 72 \mathrm{DPI})$ 


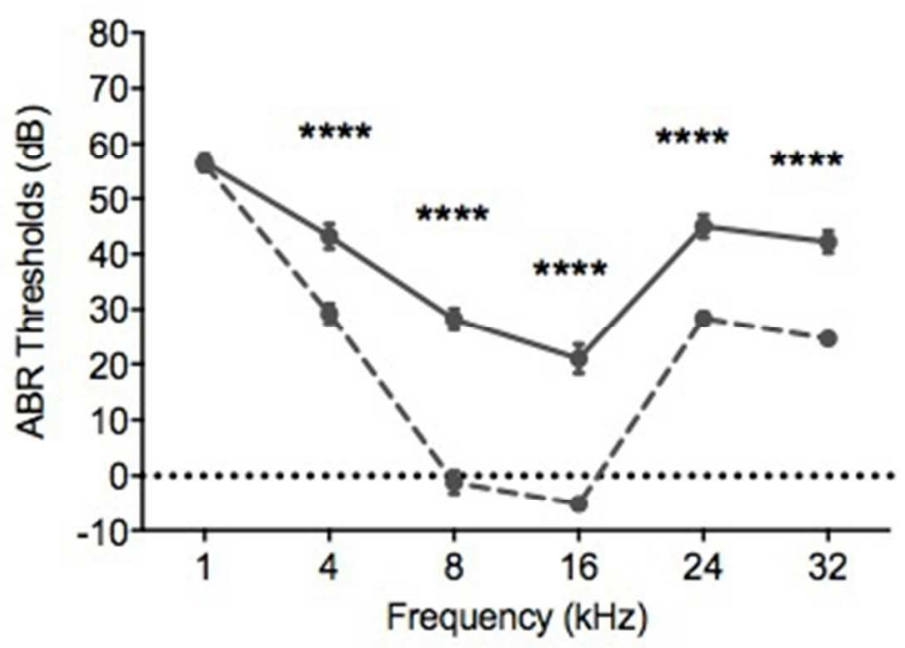

Fig. 2 Pre- and post-trauma ABR thresholds $A B R$ thresholds in all animals were recorded before (dashed line, D-2) and after (solid line, D0) noise exposure $(5 \mathrm{kHz}, 100 \mathrm{~dB}, 1 \mathrm{~h})$ and are shown for comparison (two-way ANOVA; **** $\mathrm{p}<0.0001$ Tukey's post-hoc test). Values are mean \pm SEM (25 ears).

$$
137 \times 93 \mathrm{~mm}(72 \times 72 \text { DPI })
$$





Fig. 3 Post-trauma thresholds at D7 (solid black line)

Pre-trauma ABR thresholds at D-2 (dashed gray line) and post-trauma ABR thresholds at D0 (solid gray line) are shown for comparison. ABR thresholds at D7 (solid black line) are represented by (A) control group (trapezoid, eight ears), (B) HA group (squares, six ears), (C) HA-DexP group (diamonds, six ears), (D) HADexP-Lip group (triangles, five ears). Values are mean \pm SEM. Hearing recovery was observed in the control group (A) in ABR thresholds at 16 and $24 \mathrm{kHz}$ (D7) compared to post-trauma (D0) (two-way ANOVA; $*_{p}<0.05, * * p<0.002 ;$ Tukey's post-hoc test).

$161 \times 118 \mathrm{~mm}(72 \times 72 \mathrm{DPI})$ 

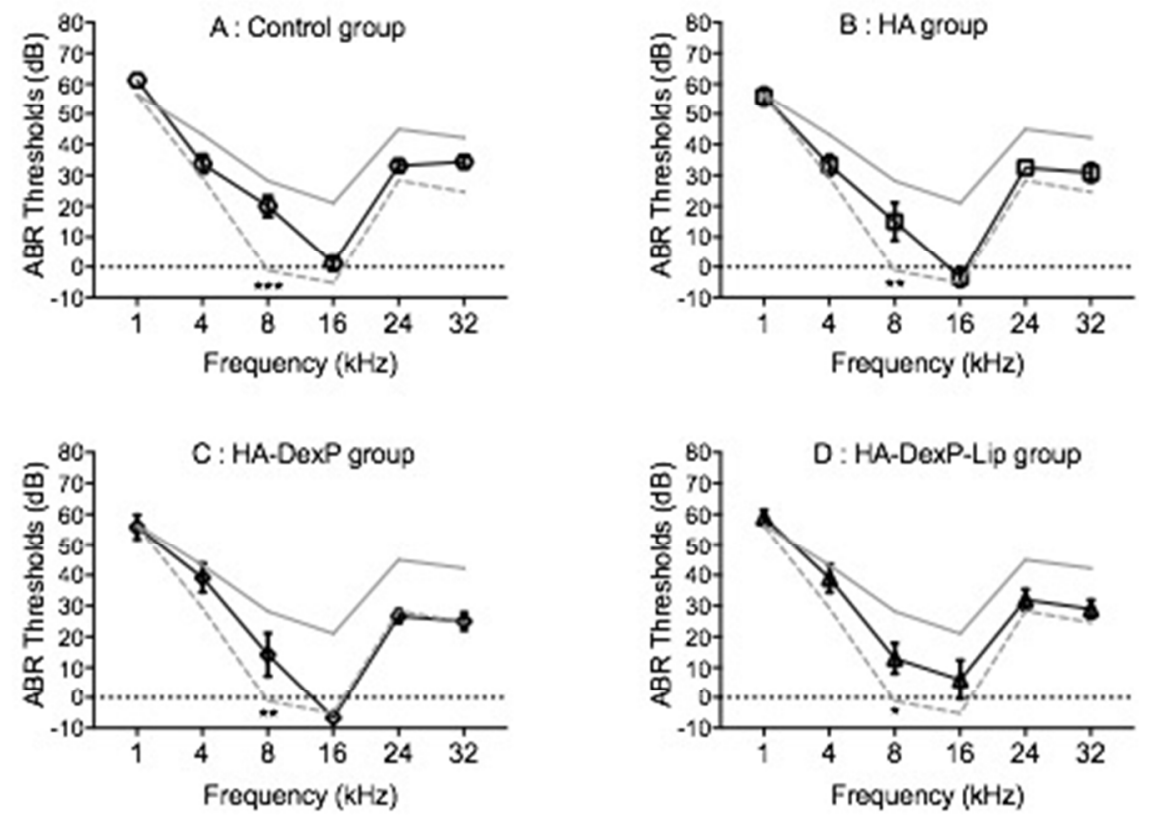

Fig. 4 Post-trauma thresholds at D30 (solid black line)

Pre-trauma ABR thresholds at D-2 (dashed gray line) and post-trauma ABR thresholds at D0 (solid gray line) are shown for comparison. ABR thresholds at D30 (solid black line) are represented by (A) control group (trapezoid, eight ears), (B) HA group (squares, six ears), (C) HA-DexP group (diamonds, six ears), (D) HADexP-Lip group (triangles, five ears). Values are mean \pm SEM. Total recovery at D30 was observed in all groups compared to pre-trauma thresholds (D-2), apart from $8 \mathrm{kHz}$ frequency in each group, with no significant differences among all groups (two-way ANOVA; ${ }^{*} p<0.02, * * p<0.002, * * * p<0.0001$ Tukey's post-hoc test).

$$
160 \times 118 \mathrm{~mm}(72 \times 72 \mathrm{DPI})
$$


Table

Table. 1 Summary of the methods and results in noise-induced hearing loss guinea pig animal model studies testing corticosteroid efficacy

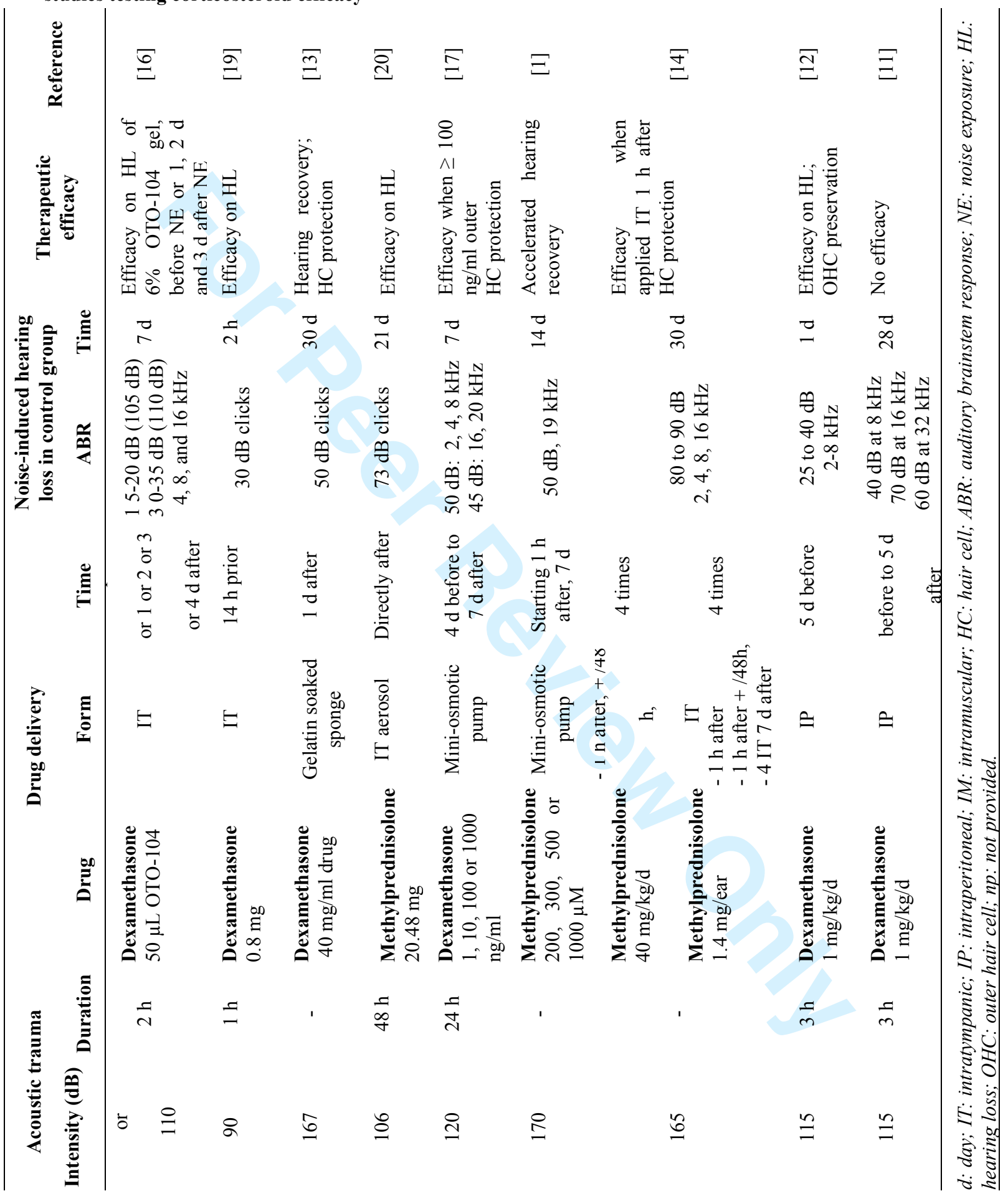




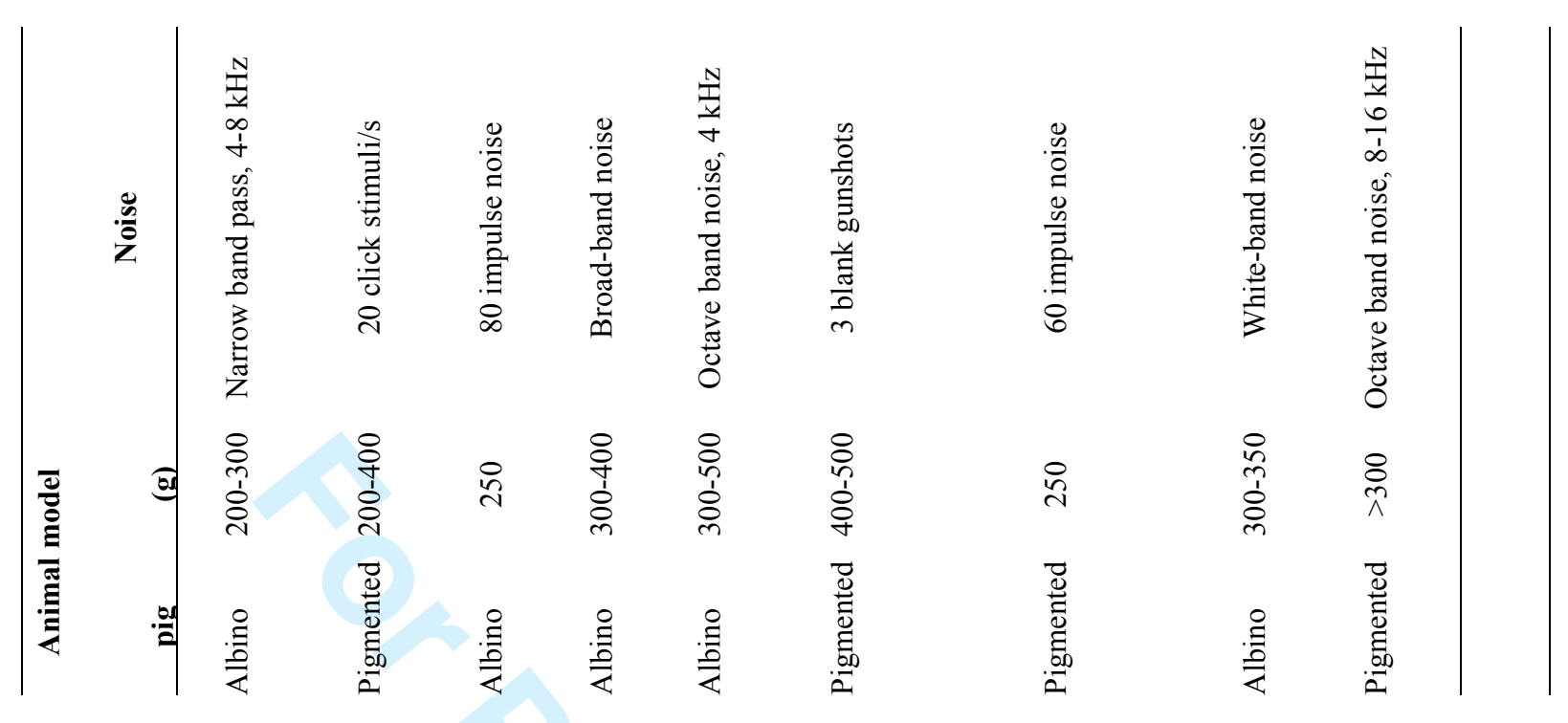 \\ Page 19 of 19}

1

2

3

4

5
6

7

8

10

11

12

13

14

15

16

17

18

19

20

21

22

24

25

26

27

28

29

30

31

32

33

34

35

36

37

38

39

40

41

42

43

44

45

46

47

48

49

50

51

52

53

54

55

56

57

58

59

60

http://mc.manuscriptcentral.com/soto Email: actaoto@informa.com 